\title{
Violência contra idosos: análise das denúncias e seu atendimento no Creas
}

\author{
Katia Simone Ploner*, Rosimar Marques Hoffmann", Fernanda de Bortoli Baldissera"*
}

\section{Resumo}

Esta pesquisa teve como objetivo principal caracterizar as denúncias de violência sofrida por idosos que foram atendidos pelo Creas de Itajaí em 2012. A análise das fichas de atendimento demonstrou que a comunicação de denúncia se deu por demanda espontânea em 63\% dos casos; que o tipo de violência predominante foi abandono/negligência (42\%); que as mulheres foram as vítimas mais acometidas (60\%); que a faixa etária da maior parte das vítimas estava entre 70 e 79 anos (40\%); que $42 \%$ das vítimas recebia um salário mínimo e que os filhos eram os suspeitos pelas agressões em 55\% dos casos. Revelou, ainda, que o tempo de espera prevalente para atendimento foi de seis a 12 meses, ocorrendo em 35\% dos atendimentos, e que $26 \%$ das denúncias não apresentava demanda para atendimento no Creas. Conhecer as características das denúncias de violência contra os idosos mostrou ser necessário para subsidiar pedidos de ampliação e modificação das políticas públicas de proteção e assistência aos idosos.

Palavras-chave: Envelhecimento. Violação de direitos. Maus-tratos. Políticas de assistência.

\section{Introdução}

Quem eram os idosos e que tipos de violência sofriam? Quem eram as pessoas suspeitas de violência contra idosos? A fim de responder essas questões de pesquisa, buscou-se o Centro de Referência Especializada de Assistência Social (Creas), no município de Itajaí, em Santa Catarina, para analisar as fichas que continham denúncias de violência sofrida por idosos.

Famílias e pessoas que se encontram em situação de ameaça ou de violação de direitos buscam o Creas como apoio. Esse órgão tem a finalidade de fortalecer vínculos e reconstruir laços familiares e comunitários, para que seja superada a situação de violação de direitos (BRASIL, 2010). Para Costa e Lopes (2014), a família tem importante papel na proteção do idoso, mas é necessário o envolvimento de toda a sociedade, de setores governamentais e não governa-

* Docente e orientadora de Iniciação Científica do curso de Psicologia na Univali (Itajaí, SC), Mestre em Psicologia Social e da Personalidade (Pucrs). E-mail: ploner@univali.br

** Alunas de iniciação científica, curso de Psicologia da Univali (Itajaí, SC). E-mails: rosihoffmann@terra.com.br e fernandabortoli@hotmail.com

$\rightarrow$ http://dx.doi.org/10.5335/rbceh.2012.4009

Recebido em: 01/06/2014. Aprovado em: 10/11/2014 
mentais, para promover uma velhice ativa e participante.

A violência contra o idoso foi definida pela Organização Mundial da Saúde (OMS) como um ato de agressão ou omissão intencional ou voluntária e, ainda, como qualquer tipo de abuso que causará, ao idoso, sofrimento, lesão, dor, perda ou violação dos direitos humanos e redução na qualidade de vida (SANCHES; LEBRÃO; DUARTE, 2008). Esse é um fenômeno complexo e de difícil controle, que ocorre em diferentes classes e atinge a ambos os gêneros (GUIMARÃES; MIRANDA; MACEDO, 2007).

Definições de categorias e tipologias foram criadas para permitir a compreensão dessas situações de violência. Essa classificação, segundo Minayo (2004), abrange maus-tratos físicos, o que consiste no uso da força física, obrigando o idoso a fazer o que não deseja; maus-tratos psicológicos, que são agressões verbais ou gestuais e que conduzem ao isolamento do convívio social; abuso financeiro ou material, que compreende a exploração imprópria ou ilegal dos bens ou do dinheiro do idoso; abuso sexual, que se refere ao ato ou jogo sexual de caráter homo ou heterorrelacional, práticas eróticas, ameaças ou violência física; negligência, que consiste na omissão de cuidados por parte dos responsáveis, familiares ou instituições; e abandono, que é a ausência dos responsáveis governamentais, institucionais ou familiares.

A realidade da violência contra o idoso apresenta características próprias do lugar onde acontece. E Itajaí tem, também, suas peculiaridades. Diferentes estudos descritos a seguir demonstram especificidades na violência contra idosos. A pesquisa realizada na cidade de Itapetininga, em São Paulo, por Prado (2010), apontou que a violência predominante foi negligência seguida de abandono e que os principais suspeitos de agressão eram os filhos. O estudo desenvolvido em Fortaleza, no Ceará (NOGUEIRA; FREITAS; ALMEIDA, 2011), assinalou, como principais vítimas, mulheres $(70,2 \%)$, com idade entre 71 e 80 anos (38\%), que residiam com o agressor $(70,4 \%)$, sendo os filhos os principais suspeitos (57,7\%). Dados obtidos em Porto Alegre (PERUHYPE; HAUSER, 2011) indicavam que as maiores vítimas também eram do sexo feminino $(69,3 \%)$, com idade entre 70 e 79 anos. E em relação às categorias de violência sofrida, a mais frequente foi a psicológica, seguida da financeira e da física, cometidas predominantemente por não familiares $(57,4 \%)$. Já no Distrito Federal, houve predomínio de violência contra idosos do sexo masculino, casados, com maior incidência de lesão corporal $(32,54 \%)$, seguida de ameaça $(30,78 \%)$, sendo que $62,81 \%$ dos agressores suspeitos eram não familiares e apenas $13,56 \%$ eram filhos (OLIVEIRA et al., 2012).

\section{Materiais e método}

este estudo, que analisou as denúncias de violência contra idosos em 2012, feitas no Creas de Itajaí, teve caráter exploratório-descritivo de cunho quantitativo-qualitativo e demonstrou que o processo de atendimento a tais denúncias tinha início com a visita da equipe técnica (psicóloga e assistente social) do Creas. 
A amostra foi constituída por 78 fichas de registro de atendimento referentes à violência contra idosos em Itajaí, analisadas, posteriormente, com a concordância do Creas registrada em Termo de Anuência. As pesquisadoras, por sua vez, assinaram um Termo de Compromisso de Utilização de Dados, firmando compromisso com o sigilo que envolve a pesquisa com seres humanos.

A coleta dos dados ocorreu entre agosto e setembro de 2013. O instrumento utilizado foi um roteiro com perguntas fechadas, visando acessar as seguintes informações: a origem da denúncia, o denunciante, o tipo de violência, a data em que a denúncia foi realizada, o tempo que a demanda levou para ser atendida, o perfil do idoso vítima da violência (sexo, idade, renda, estado civil), a identificação do acusado pela agressão e a resolutividade. As informações recolhidas nas fichas foram tabuladas (Excel) e mensuradas as frequências relativa (percentual) e absoluta (números totais) dos eventos registrados. Os dados não identificados (NI) foram considerados na análise.

A assistente social e a psicóloga responsáveis pelos idosos do Creas/ Itajaí participaram da adequação do instrumento de coleta de dados. A coordenadora do Creas foi entrevistada para auxiliar na compreensão dos dados e concordou em participar da pesquisa, assinando o Termo de Consentimento Livre e Esclarecido (TCLE).

O projeto de pesquisa foi submetido ao Comitê de Ética e Pesquisa da Universidade do Vale do Itajaí (Univali) para apreciação, sendo aprovado sob o número CAAE 18646113.0.0000.0120.

\section{Resultados e discussão}

\section{Caracterização da denúncia}

Denunciar a violência contra os idosos, principalmente a doméstica, é reconhecidamente difícil. Estima-se que apenas uma pequena porcentagem seja notificada aos órgãos responsáveis e muitas vezes isso só ocorre em função da gravidade do acontecimento (PASINATO; MACHADO; CAMARANO, 2004).

Os resultados mostraram que $63 \%$ $(\mathrm{n}=52)$ dos casos denunciados se deram por demanda espontânea (familiares, vizinhos, o próprio idoso ou outra pessoa) e que, para algumas ocorrências, houve mais de um comunicante. Compreende-se por demanda espontânea o movimento das pessoas que procuram o Creas voluntariamente para fazer uma denúncia.

O Ministério da Saúde define que a demanda espontânea é construída socialmente, portanto, é flexível e não deve ser naturalizada (BRASIL, 2001). Para Mattos (2004), apesar de ser construída socialmente, a demanda espontânea é vivenciada individualmente. Ela surge a partir de uma experiência de sofrimento e de uma expectativa de resolução para amenizar tal padecimento.

Os encaminhamentos de denúncias feitos pelo Disque 100 totalizaram 13\% $(\mathrm{n}=11)$; aqueles feitos por meio da Promotoria Pública, 4\% ( $\mathrm{n}=3)$; e os demais serviços da rede de proteção municipal, como a Secretaria da Saúde ou Creas, receberam o que representou, no todo, $18 \%(\mathrm{n}=15)$ do volume das denúncias.

O tempo de espera para que a denúncia fosse atendida também foi analisado. 
$\mathrm{O}$ resultado mais significativo foi de $35 \%$ $(n=27)$, que correspondeu ao período de seis a 12 meses. A demora no atendimento da denúncia parece resultar no aumento dos casos de violência, o que pode ter como causa a impunidade. O tempo que se leva para a resolução dos casos de violação dos direitos humanos compromete $o$ andamento dos processos e o desfecho desses (ADORNO; PASINATO, 2007).

Nesta pesquisa foi possível constatar que em menos de um mês foram atendidos $12 \%(\mathrm{n}=9)$ dos casos. Nas demais ocorrências, $12 \%(\mathrm{n}=9)$ foram atendidas entre um e três meses, $15 \%(n=12)$ entre três e seis meses, e o mesmo índice, $15 \%$ da amostra, recebeu atendimento no prazo de 12 meses. Verificou-se, nas fichas de denúncias de violência contra os idosos, que esses atendimentos vieram do Ministério Público, diretamente, ou via rede de atendimento do município.

A coordenadora do Creas relatou, em entrevista, que, em março de 2013, o serviço de proteção ao idoso estava com um ano e meio de atraso nos atendimentos, ou seja, no mês em questão, a equipe técnica (psicóloga e assistente social) estava finalizando os atendimentos referentes ao ano de 2011. Afirmou, ainda, que havia necessidade de mais profissionais para atender os idosos do município, pois, no momento deste estudo (setembro de 2013), a equipe era composta apenas por uma assistente social e uma psicóloga. A entrevistada, o Conselho Municipal do Idoso e a Secretaria de Desenvolvimento Social estavam tentando, junto à Prefeitura Municipal, a abertura de concursos públicos para a contratação de mais profissionais para a rede socioassistencial. Deduziu-se que, havendo efetivo maior, seria possível atender às denúncias no mesmo mês em que fossem registradas.

A inacessibilidade à proteção social do idoso pode ter ligação com a falta de estrutura de defesa nos níveis municipais, como também com a omissão da equipe técnica (BORBA, 2011). Esses fatores podem ter influência no tempo de atendimento dos casos de violência contra o idoso.

A violência sempre existiu. Em todos os tempos e em todas as sociedades está registrada como uma das maneiras de resolver conflitos entre as pessoas, na família, na comunidade e entre os países. Frequentemente, costuma ser relacionada à pobreza; porém, sua complexidade $\mathrm{e}$ seu crescimento nas cidades têm levado a considerá-la como o resultado da junção de vários aspectos, entre eles, o processo de urbanização. Os diferentes territórios da cidade expressam as relações sociais vigentes de acordo com a época em que foram produzidas (FERREIRA; PENNA, 2005).

\section{Tipos de violência}

No Creas do município de Itajaí, a violência contra os idosos se apresentou do modo como pode ser visto na Tabela 1 . 
Tabela 1: Tipos de violências notificadas no município de Itajaí - SC/2012

\begin{tabular}{l|c|r}
\hline Tipo de violência notificada & Frequência & \multicolumn{1}{c}{$\%$} \\
\hline Abandono/ negligência & 45 & 42 \\
Violência psicológica & 21 & 19 \\
Violência patrimonial & 16 & 15 \\
Violência física & 14 & 13 \\
Autonegligência & 6 & 6 \\
Violência sexual & 1 & 1 \\
NI & 5 & 5 \\
Total & 108 & 100 \\
\hline
\end{tabular}

Fonte: Prontuário de atendimento ao idoso do Creas Itajaí - 2012.

O número total das ocorrências era maior do que o número de fichas analisadas, pois em alguns casos, o mesmo idoso sofreu mais de um tipo de violência. "Esse dado condiz com outros estudos que ressaltam que os diversos tipos de maus-tratos se articulam" (SCHRAIBER et al. , 2006 apud NOGUEIRA; FREITAS; ALMEIDA, 2011, p. 550).

Os dados demonstram que a violência predominante foi por abandono e negligência (42\%), seguida de violência psicológica (19\%) e de violência patrimonial (15\%), e esses dados, estatisticamente, são semelhantes aos de outros estudos nacionais. Em Itapetininga, São Paulo, em primeiro lugar, aparece a negligência (25 casos) como o tipo de violência com maior número de ocorrências; em segundo, o abandono, com 13 casos; e a financeira ficou com 11 registros (PRADO, 2010). Em Fortaleza, no Ceará, em primeiro lugar, está a violência psicológica; em segundo, a negligência; e em terceiro, a econômica (NOGUEIRA; FREITAS; ALMEIDA, 2011).

A violência institucional não foi registrada, pois não é atendida pelo Creas e essas denúncias são encaminhadas para o Conselho Municipal do Idoso.

A vítima

Identificar o perfil da vítima pode auxiliar no desenvolvimento de políticas de proteção a essa população. A pesquisa forneceu alguns dados sobre o perfil registrado nas fichas do Creas/Itajaí.

Quanto ao gênero, 60\% $(n=47)$ das vítimas eram mulheres e $37 \%(\mathrm{n}=29)$ eram do sexo masculino. Em duas fichas, o item sexo não foi informado, totalizando $3 \%$ de idosos não identificados por essa característica. Quanto à faixa etária da pessoa idosa que mais sofria violência em Itajaí, estava entre 70 e 79 anos, em $40 \%(n=31)$ dos casos. Também foram identificadas pessoas na faixa etária de 80 a 89 anos, em $27 \%(n=21)$ dos casos, e de 60 a 69 anos, em $24 \%(n=19)$.

Estudo realizado no ano de 2010, a partir do Sistema de Informação de Agravos de Notificação (SINAN NET), afirma que a violência é identificada com maior frequência em idosos de 60 a 69 anos, e que estes, em sua maioria, são mulheres (MASCARENHAS et al., 2012).

Sobre a situação socioeconômica da pessoa idosa vítima de violência, identificou-se que $42 \%$ têm renda de até um salário mínimo. Estudos entre países de diferentes culturas revelam que pessoas de qualquer condição socioeconômica estão vulneráveis à violação dos direitos que ocorre de diversas formas, como 
física, sexual, emocional e financeira (SOUZA; FREITAS; QUEIROZ, 2007).

Em relação ao estado civil da pessoa idosa vítima de violência, em $42 \%(n=33)$ das fichas esse não foi registrado. Mas $19 \%$ foram identificados como viúvos e $6 \%$, como casados. Pesquisa realizada na Delegacia Especial de Atendimento ao Idoso (Deati), em Salvador, revela que, no ano de $2008,65,4 \%$ dos idosos vítimas de violência eram solteiros, $27,1 \%$ eram casados, $6 \%$, divorciados e $1,5 \%$, viúvos (PINHEIRO; SILVA; ANDRADE, 2011).

Além de dar a conhecer o perfil da vítima, esta pesquisa possibilitou que se conhecesse também o possível suspeito da agressão.

\section{0 agressor suspeito}

O inciso I do artigo $3^{\circ}$ da lei $n$. 8.842/94 dispõe que "a família, a sociedade e o Estado têm o dever de assegurar ao idoso todos os direitos da cidadania, garantindo sua participação na comunidade, defendendo sua dignidade, o bem-estar e o direito à vida". Nos dias de hoje, porém, o maior índice de violência contra os idosos ocorre no âmbito familiar, de quem se esperava proteção (BRASIL, 2010b, p. 7).

O número absoluto dos suspeitos de violência contra a pessoa idosa registrado pelo Creas no município de Itajaí foi de 88 , pois, em vários casos, havia mais de um suspeito de agressão, evidenciado na Tabela 2.
Tabela 2: Agressor suspeito de violência contra idosos - Itajaí- SC/2012

\begin{tabular}{l|r|r}
\hline Suspeito da agressão & Frequência & \multicolumn{1}{|c}{$\%$} \\
\hline Cônjuge & 2 & 2 \\
Filho (a) & 48 & 55 \\
Neto (a) & 6 & 7 \\
Outros familiares & 11 & 13 \\
Vizinho/amigo & 2 & 2 \\
Cuidadores & 3 & 3 \\
Própria pessoa & 3 & 3 \\
Desconhecido & 1 & 1 \\
NI & 12 & 14 \\
Total & 88 & 100 \\
\hline
\end{tabular}

Fonte: Prontuário de atendimento ao idoso do Creas Itajaí - 2012.

Os filhos foram apontados como os principais suspeitos de agressão, seguidos de "outros familiares", reconhecidos como nora, genro, irmão(a), cunhado(a) e sobrinho(a). Minayo (2004) comenta que pesquisas realizadas em diversos países revelam que o maior número de agressores contra pessoas idosas são filhos, cônjuges e netos. Em concordância com o argumento da autora, pesquisa realizada no Distrito Federal aponta que, no mapa da violência contra a pessoa idosa, "pesquisas nacionais e internacionais revelam que $2 / 3$ dos agressores são filhos e cônjuges" (BRASIL, 2013, p. 30).

A violência intrafamiliar nos dias atuais é um fenômeno complexo e acontece em diversos países, sem distinção de religião, raça, classe, etnia ou cultura e pode estar associada a questões sociais, econômicas, culturais e de saúde, em um 
contexto no qual os familiares podem não saber como agir (GONDIM, 2011).

\section{Encaminhamentos / resolutividade}

Observou-se, nas fichas de registro de atendimentos do Creas, diferentes motivos para desligamento desse serviço, sendo que $27 \%(\mathrm{n}=21)$ das denúncias "não apresentam demanda para o atendimento especializado", ou seja, referem-se a: a) discussões familiares sem caráter de violação de direitos; b) conflitos familiares sem o envolvimento da pessoa idosa; c) desistência do denunciante ou do próprio idoso ou negação do teor do processo; d) denúncias que se tornam processos judiciais e que vão percorrer um longo caminho até serem realmente solucionadas.

Tabela 3: Motivo de desligamento dos casos no Creas no município de Itajaí - SC/2012

\begin{tabular}{l|c|c}
\hline \multicolumn{1}{c|}{ Motivo do desligamento do caso do serviço } & Frequência & $\%$ \\
\hline Não apresenta demanda para o atendimento especializado & 21 & 27 \\
Encaminhamento para a rede (institucionalização) & 16 & 21 \\
Falecimento da pessoa idosa & 15 & 19 \\
Mudança de endereço & 10 & 13 \\
Situação que gerou a notificação foi superada & 5 & 6 \\
Não adesão à proposta do serviço & 2 & 3 \\
NI & 9 & 12 \\
Total & 78 & 100 \\
\hline
\end{tabular}

Fonte: Prontuário de atendimento ao idoso do Creas Itajaí - 2012.

Em $21 \%(n=16)$ dos casos, os idosos foram encaminhados para a "rede de institucionalização de longa permanência”. A Anvisa reconhece as ILPIs como instituições governamentais ou não governamentais, com caráter residencial para pessoas com idade igual ou superior a 60 anos, que tenham ou não suporte familiar (CAMARANO; KANSO, 2010).

Em comparação, estudo realizado por período de 12 meses, pelo governo do estado do Rio de Janeiro, identificou que entre 308 denúncias de maus-tratos a pessoas idosas, 120 foram resolvidas
(39\%), o que evidencia que também há dificuldades nos serviços de assistência a essa população (ALVES, 2001).

Outro resultado relevante foi o falecimento da pessoa idosa em $19 \%(n=15)$ dos casos. Ao analisar especificamente essas fichas, observou-se que sete pessoas idosas esperaram de seis a 12 meses para receber o atendimento do Creas e cinco esperaram mais de 12 meses. Logo, se 12, das 15 pessoas que faleceram, esperaram mais de seis meses para serem atendidas, deduz-se que o tempo de espera para atendimento contribui com esse dado. 
A demora no processo de implementar o serviço de proteção social ao idoso provoca, em muitos casos, a desistência da denúncia e até mesmo o óbito do idoso, o que pode sinalizar baixa resolutividade dos casos (NOGUEIRA; FREITAS; ALMEIDA, 2011).

Ao somar os casos de mudança de endereço (13\%) com os de não adesão ao serviço (3\%) e os de o falecimento da pessoa idosa (19\%), temos $35 \%$ de ocorrências sem resolutividade ou encaminhamento. Em 6\% dos casos, a situação que gerou a notificação foi superada, ou seja, a família e/ou a situação já tinham se organizado.

Foi possível notar que ainda há muito por fazer para articular uma rede de proteção social aos idosos com direitos violados, pelo menos nesse local e tempo histórico.

\section{Considerações finais}

A pesquisa atingiu os objetivos na medida em que possibilitou compreender melhor como se dá a violência contra os idosos, demonstrando que a denúncia é realizada por demanda espontânea, tem como tipo predominante abandono e negligência, e as vítimas têm como perfil serem pessoas idosas menos favorecidas, em sua maioria, mulheres, na faixa etária de 70 a 79 anos. Além disso, mostra que os maiores suspeitos das agressões são os(as) filhos(as). Esses dados devem servir para subsidiar as políticas públicas, permitindo que essas se deem em bases reais e concretas em favorecimento dessa população.

Pressupõe-se que a população está sentindo mais segurança em buscar auxílio em instituições que prestam assistência social e está se apropriando das políticas públicas dessa natureza. Porém, questiona-se por que essas denúncias pouco chegam ao Creas por meio de outros órgãos municipais que também prestam assistência aos idosos?

O tempo de espera para atendimento trouxe muitas preocupações. Esperar entre seis meses e um ano faz com que o idoso sinta-se mais fragilizado. Já é difícil passar por uma situação de violência, e se há demora no atendimento após esse doloroso processo, ocorre o agravamento da circunstância. Aqui entendemos que o idoso que, após a denúncia, continua submetido à situação que a gerou, passa a sofrer também de violência psicológica.

A palavra resolutividade remete à ideia de solução de problemas; resolver, porém, nem sempre é extinguir a questão, mas, possibilitar que se encontrem meios que possam minimizar os conflitos. O índice de $35 \%$ de casos que foram desligados por falecimento, mudança de endereço ou queixa inadequada reflete a necessidade de mais apoio para esse serviço e esclarecimento acerca de seu papel e de suas atribuições à população e aos órgãos municipais. Cogitou-se a hipótese de que se a demanda viesse da rede de proteção municipal (Cras, ESF, Promotoria, Delegacia, Unidades de Saúde), ou seja, se os serviços estivessem articulados, talvez houvesse maior resolutividade para os casos.

As famílias têm ficado menores e mais dispersas regionalmente, com as mulheres e homens adultos trabalhando fora de casa, o que promove pouca possibilidade de apoio ao idoso doente ou vulnerável, evidenciando a síndrome da 
família insuficiente. Quando a família não se faz presente e/ou o município não tem mais vagas nas poucas instituições disponíveis para idosos, os profissionais se veem com poucas opções de ação.

A violência contra os idosos é um tema de grande relevância social e, apesar de ser discutido em todo país, cada região tem suas características particulares. Os Conselhos do Idoso aos níveis nacional, estadual, municipal e do Distrito Federal, conforme lei 8.842, de 1994, zelam pelo cumprimento dos direitos desses indivíduos.

\section{Violence Against Elderly: Analysis of Complaints And Its Service By Creas}

\section{Abstract}

This study meant to characterize the reports of violence suffered by seniors who were assisted by CREAS of Itajaí in 2012. The analysis of medical charts showed that the communication of the complaint spontaneous occurred in $63 \%$ of cases; the predominant type of violence was the abandonment/neglect $(42 \%)$; that the women were the most affected victims (60\%); that the age of most of the victims ranged between 70 and 79 years $(40 \%)$; that $42 \%$ of victims received minimum wage and that the children were suspected of aggression in 55\% of cases. Revealed also that the waiting time for service prevalent were six to 12 months, occurred in $35 \%$ of the cases and $26 \%$ of the complaints presented no demand for care in CREAS. Know the characteristics of complaints of violence against the elderly proved to be necessary to support requests for extension and modification of public policies for the protection and assistance for the elderly.

Keywords: Aging. Violation of rights. Maltreatment. Politic Assistance.

\section{Referências}

ADORNO, S.; PASINATO, W. A justiça no tempo, o tempo da justiça. Revista de Sociologia da USP, São Paulo, v. 19, n. 2, p. 131-155, nov. 2007. Disponível em: <http:// www.scielo.br/pdf/ts/v19n2/a05v19n2.pdf>. Acesso em: 8 nov. 2013.

ALVES, A. M. A construção social da violência contra os idosos. Textos Envelhecimento, Rio de Janeiro, v. 3, n. 6, p. 9-31, 2001. Disponível em: <http://revista.unati.uerj.br/ scielo.php?script $=$ sci_arttext\&pid $=\mathrm{S} 1517$ $-59282001000200002 \& \operatorname{lng}=$ pt\&nrm $=$ iso $>$. Acesso em: 27 out. 2013.

BORBA, R. D. C. F. Um estudo sobre a estruturação da rede de proteção social voltada à população idosa no município de Vitória. 2011. 169 f. Dissertação (Mestrado em Política Social) - Universidade Federal do Espírito Santo, Vitória, 2011. Disponível em: <http://web3.ufes.br/ppgps/sites/web3. ufes.br.ppgps/files/Roberta\%20Daniel\%20 Borba.pdf>. Acesso em: 8 nov. 2013.

. Ministério da Saúde. Política nacional de redução da morbimortalidade por acidentes e violências. Portaria GM/MS n ${ }^{-}$ 737 de 16/05/01 publicada no DOU no 96, seção 1e, Brasília, 2001. Disponível em: <http://portal.saude.gov.br/portal/arquivos/ pdf/politica_promocao.pdf $>$. Acesso em: 7 nov. 2013.

Ministério do Desenvolvimento Social e Combate à Fome. Centro de Referência Especializado de Assistência Social (CREAS). Brasília/DF, 2010. Disponível em: <http:// www.mds.gov.br/assistenciasocial/protecaoespecial/creas > . Acesso em: 10 mar. 2013.

Ministério do Desenvolvimento Social e Combate à Fome. Política Nacional do Idoso. Lei no 8.842, janeiro de 1994, n. 1, Brasília/DF. 2010b. Disponível em: <http:// itica-nacional-do-idoso/Politica\%20Nacional\%20do\%20Idoso.pdf/download $>$. Acesso em: 22 out. 2013. 
Tribunal de Justiça do Distrito Federal e dos Territórios. O mapa da violência contra a pessoa idosa no Distrito Federal. Brasília: MPDFT, 2013. Disponível em: <http://www.tjdft.jus.br/acesso-rapido/ acoes/acesso-a-justica-e-cidadania/central-do-idoso/mapadaviolenciacontraoidoso.pdf $>$. Acesso em: 28 out. 2013.

CAMARANO, A.; KANSO, S. As instituições de longa permanência para idosos no Brasil. Revista Brasileira de Estudos de População, Rio de Janeiro, v. 27, n. 1, p. 233-235, jan./ jun. 2010. Disponível em: <http://www.scielo. br/pdf/rbepop/v27n1/14.pdf>. Acesso em: 28 out. 2013.

COSTA, A. M. M. R.; LOPES, R. G. da C. Rede de suporte social na velhice: para além da família e dos amigos. $R e$ vista Portal de Divulgação, São Paulo, v. 4, n. 40, p. 110-119, mar./abr./maio 2014. Disponível em: <http://portaldoenvelhecimento.org.br/revista-nova/index.php/revistaportal/article/viewFile/451/451>. Acesso em: 8 set. 2014 .

DATASUS. Informações de Saúde. População residente em Santa Catarina. Ministério da Saúde. Brasília, 2012. Disponível em: <http:// tabnet.datasus.gov.br/cgi/deftohtm.exe?ibge/ cnv/popsc.def $>$. Acesso em: 10 nov. 2013.

FERREIRA, I. C. B.; PENNA, N. A. Território da violência: um olhar geográfico sobre a violência urbana. Revista Espaço e Tempo, São Paulo, n. 18, p. 155-168, 2005. Disponível em: $<$ http://citrus.uspnet.usp.br/geousp/ojs2.2.4/ index.php/geousp/article/view/371/201>. Acesso em: 5 nov. 2013.

FLORENCIO, M. V. D. L.; FERREIRA FILHA, M. O.; SÁ, L. D. A violência contra o idoso: dimensão ética e política de uma problemática em ascensão. Revista Eletrônica de Enfermagem, UFG, Goiânia, v. 9, n. 3, p. 847857, set./dez. 2007. Disponível em: <http:// www.fen.ufg.br/revista/v9/n3/v9n3a23.htm>. Acesso em: 8 nov. 2013.

FLORES, M. A. As políticas públicas de atendimento às crianças e adolescentes vítimas de violência sexual no município de Itajaí (SC), a partir das recentes reformulações da política social brasileira. 2010. 159 f. Dissertação (Mestrado Profissional em Gestão de Políticas Públicas) - Universidade do Vale do Itajaí, Itajaí, 2010. Disponível em: <http:// siaibib01.univali.br/pdf/Maqueline $\% 20$ de\%20Almeida\%20Flores.pdf $>$. Acesso em: 8 nov. 2013.

FONSECA, M. M.; GONÇALVES, H. S. Violência contra o idoso: suportes legais para a intervenção. Revista Interação em Psicologia, UFPR, Curitiba, v. 7, n. 2, p. 121-128, 2003. Disponível em: <http://ojs.c3sl.ufpr.br/ojs/ index.php/psicologia/article/view/3230>. Acesso em: 28 set. 2013.

GONDIM, L. V. Violência intrafamiliar contra o idoso: uma preocupação social e jurídica. Revista Acadêmica da Escola Superior do Ministério Público do Ceará, Fortaleza, v. 3, n. 2, ago./dez. 2011. Disponível em: <http://www.mpce.mp.br/esmp/publicacoes/ edi002_2011/artigos/04-Violencia.Intrafamiliar.Contra.o.Idoso.pdf>. Acesso em: 28 out. 2013.

GUIMARÃES, S. J.; MIRANDA, J. L. S.; MACEDO, L. T. A. Violência contra o idoso: questão social a ser discutida. In: JORNADA INTERNACIONAL DE POLÍTICAS PÚBLICAS, 3, São Luís - MA, 28 a 30 de agosto 2007, Programa de Pós-graduação em Políticas Públicas. Anais... São Luis: UFMA, 2007, p. 1-9. Disponível em: <http:// www.joinpp.ufma.br/jornadas/joinppIII/html/ Trabalhos/EixoTematicoF/52cce56baa935ab 80c1cSimone_jakelinne_Livia.pdf $>$. Acesso em: 25 abr. 2013.

MASCARENHAS, M. D. M. et al. Violência contra a pessoa idosa: análise das notificações realizadas no setor saúde - Brasil, 2010. Revista Ciência e Saúde Coletiva. Rio de Janeiro, v. 17, n. 9. p. 2331-2341, set. 2012. Disponível em: <http://portalsaude.saude. gov.br/portalsaude/arquivos/pdf/2013/Abr/03/ art_violencia_csc_2012_violencia_contra_ idosos_sinan_brasil2010.pdf>. Acesso em: 3 nov. 2013. 
MATTOS, R. A. A integralidade na prática (ou sobre a prática da integralidade). $C a$ dernos de Saúde Pública, Rio de Janeiro, v. 20, n. 5, p. 1411-1416, out. 2004. Disponível em: <http://www.scielo.br/pdf/csp/v20n5/37. pdf>. Acesso em: 8 nov. 2013.

MINAYO, M. C. S. Violência contra idosos: o avesso do respeito à experiência e à sabedoria. Brasília: DF. Secretaria Especial dos Direitos Humanos, 2004. Disponível em: <http://www.observatorionacionaldoidoso. fiocruz.br/biblioteca/_manual/4.pdf $>$. Acesso em: 22 out. 2013.

NOGUEIRA, C. F.; FREITAS, M. C.; ALMEIDA, P. C. Violência contra idosos no município de Fortaleza, CE: uma análise documental. Revista Brasileira de Geriatria e Gerontologia, Rio de Janeiro, v. 14, n. 3, p. 543-554, 2011. Disponível: <http://revista. unati.uerj.br/pdf/rbgg/v14n3/v14n3a13.pdf>. Acesso em: 28 out. 2013.

OLIVEIRA, M. L. C. de et al. Características dos idosos vítimas de violência doméstica no Distrito Federal. Revista Brasileira de Geriatria e Gerontologia, Rio de Janeiro, v. 15, n. 3, p. 555-566, jul./set. 2012. Disponível em: <http:/www.scielo.br/scielo.php?script=sci_ arttext\&pid=S1809-98232012000300016\&ln $\mathrm{g}=\mathrm{en} \& \mathrm{nrm}=\mathrm{iso}>$. Acesso em: 9 set. 2014.

PASSINATO, M. T.; MACHADO, L.; CAMARANO, A. A. Idosos vítimas de maus-tratos domésticos: estudo exploratório das informações dos serviços de denúncia. In: ENCONTRO NACIONAL DE ESTUDOS POPULACIONAIS - ABEP, 15, Caxambu, 2004. Anais... Caxambu (MG), 2004. Disponível em: <http://www.observatorionacionaldoidoso.fiocruz.br/biblioteca/_artigos/17. pdf>. Acesso em: 15 maio 2012.

PERUHYPE, R. C.; HAUSER, L. Análise do perfil sociodemográfico de idosos vítimas de violência no município de Porto Alegre/ RS/Brasil. Revista Brasileira de Geriatria e Gerontologia, Rio de Janeiro, v. 5, n. 4, p. 220-225, 2011. Disponível em: <http:// www.sbgg.org.br/profissionais/arquivo/ revista/ciclo-editorial/artigo07.pdf>. Acesso em: 8 set. 2014 .

PINHEIRO, J. S.; SILVA, R. C.; ANDRADE, M. C. Perfil dos idosos que sofreram violência atendidos em uma instituição de Salvador no ano de 2008. Revista de Saúde Pública, São Paulo, v. 35, n. 2, p. 264-276, abr./jun. 2011. Disponível em: <http://files.bvs.br/ upload/S/0100-0233/2011/v35n2/a2441.pdf>. Acesso em: 3 nov. 2013.

PRADO, I. A experiência de Itapetininga no enfrentamento à violência contra a pessoa idosa. Revista Portal da Divulgação, n. 2, set. 2010. Disponível em: <http://portaldoenvelhecimento.org.br/revistanova/index.

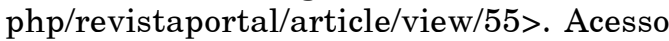
em: 10 nov. 2013.

SANCHES A. P.; LEBRÃO, M. L.; DUARTE, Y. A. O. Violência contra os idosos: uma visão nova. Revista Saúde e Sociedade. São Paulo, v. 17, n. 3, p. 90-100, 2008. Disponível em: $<$ http://www.scielo.br/pdf/sausoc/v17n3/10. pdf>. Acesso em: 21 mar. 2013.

SOUZA, J. A. V.; FREITAS, M. C.; QUEIROZ, T. A. Violência contra os idosos: Análise documental. Revista Brasileira de Enfermagem, Brasília, v. 60, n. 3, p. 268-272, 2007. Disponível em: <http://www.scielo.br/pdf/reben/ v60n3/a04.pdf>. Acesso em: 28 out. 2013. 